\title{
Better sleep, better health for shift workers
}

I $\mathrm{t}$ is a work-related problem shared by doctors and nurses, train engineers, police officers, pilots and astronauts. And the list doesn't end there.

"Approximately $25 \%$ of the active work population has a work schedule that affects their sleep," says Marie Dumont, a Université de Montréal psychiatry professor who studies sleep, circadian rhythms and adaption disorders of night workers and night owls.

To help workers cope with the effects of shift work, the scientific community has traditionally opted for resetting their circadian or biological clocks with doses of bright light, effectively turning night into day. But if they return to working days as part of a rotating schedule, "we have to do it again," says Dumont.

"The adaption is an unstable state that can last a few days and during that time the different clocks in the body are desynchronized," Dumont says. "We think this unstable state is worse for the health of the night worker."

Dumont says her research indicates a partial shift of the biological clock may be a better solution. "What we want to do now is find a compromise position for the biological clock of night workers so they are never completely adapted to night work and never adapted to day work. They are in between, but their clock is not changing all the time ... which is an unstable state that is very unhealthy."

Dumont was one of about 100 scientists, researchers and lighting experts at a recent meeting of the Commission Internationale de L'Eclairage (International Commission on Illumination) in Toronto. Dedicated to the science of light, this independent organization has been seen as the global authority on lighting since its inception in 1913. The United Nations has declared 2015 as the International Year of Light and LightBased Technologies to raise awareness about how light affects our daily lives and to explore lighting solutions to challenges in energy, education, agriculture and health.

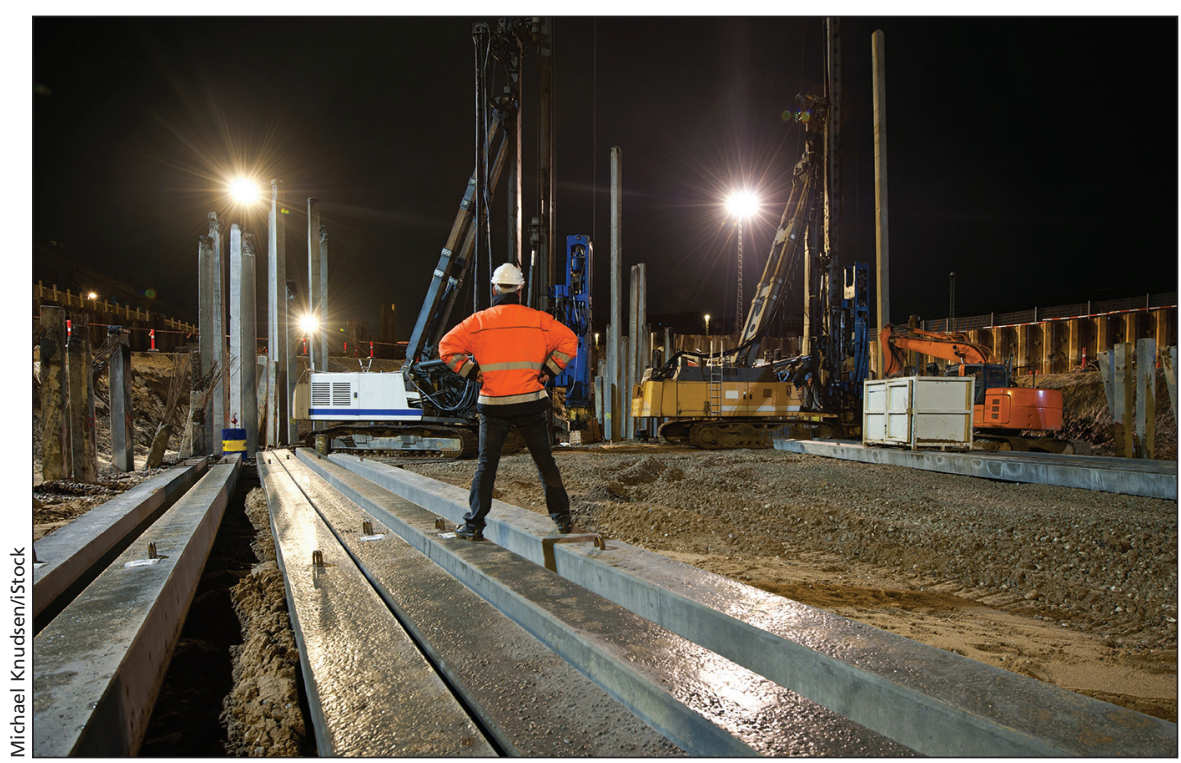

About a quarter of the active work population has a schedule that affects their sleep.

According to Dumont, the scientific community has known for some time that night work is associated with many negative, short-term health effects, such as weight gain, increased cholesterol levels and problems with vigilance and digestion. Recent research also points to possible long-term problems, including a "modest increase" in lung cancer and cardiovascular disease mortality. Overall, however, the body of evidence linking shift work to chronic diseases (breast cancer, diabetes, cardiovascular disease) is "suggestive but not conclusive."

George Brainard, director of the Light Research Program at Thomas Jefferson University in Philadelphia, agrees that sleep loss is a "big problem" for shift workers, and particularly for those in high-risk professions, such as astronauts. He is working with the National Aeronautics and Space Administration (NASA) to figure out how astronauts in orbit can get the sleep they need, during the day or night.

"If you're losing an hour to an hourand-a-half, night after night, week after week - or in terms of the space station month-after-month, for a possible threeyear Mars mission — that's serious, chronic, partial sleep deprivation," says
Brainard. "You're in a high-tech, highrisk environment where errors in psychomotor ability and judgment can threaten the safety of the astronaut and the safety of the entire mission."

According to Brainard, many astronauts rely on pharmaceuticals to get to sleep. He is working, however, on a lighting system for the space station to help astronauts sleep better, technology that could also have future applications down on earth.

"We are in the early stages of a true revolution in architectural lighting," he says. "We're beginning with hospital lighting, where the goal is to improve the health and well-being, and decrease the length of stay, of hospital patients."

In the meantime, Dr. Brainard has a piece of advice for sleep-deprived astronauts: stop watching all those sunrises. "As you are going around the planet, you have a sunrise and a sunset every 90 minutes," he says. "It's a perk of being up there, but you don't want to compromise your sleep by watching the sunrise just before you go to bed. That's going to delay your capacity to go to sleep." — Becky Rynor, Toronto, Ont.

CMAJ 2016. DOI:10.1503/cmaj.109-5202 